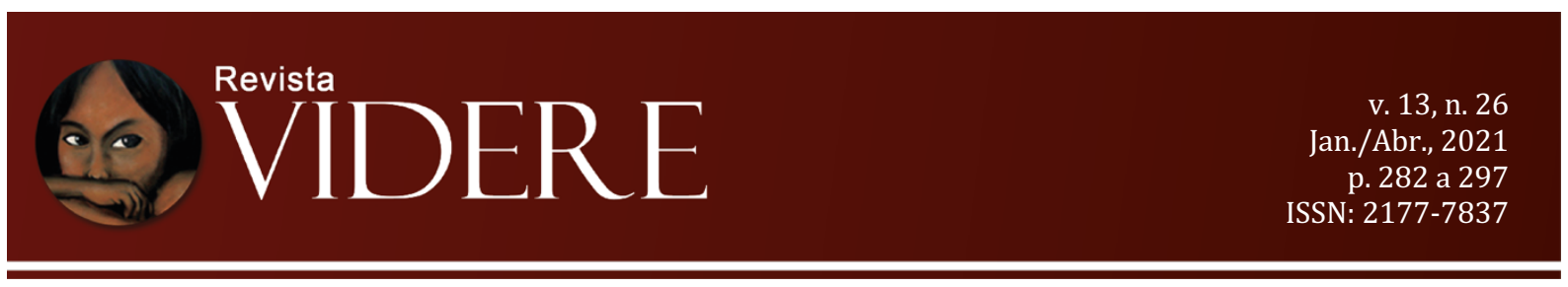

\title{
O DIREITO DE ACESSO À JUSTIÇA PARA AS MULHERES INDÍGENAS NO ESTADO PLURINACIONAL BOLIVIANO
}

\author{
THE RIGHT OF ACCESS TO JUSTICE FOR INDIGENOUS WOMEN IN THE \\ BOLIVIAN PLURINATIONAL STATE
}

\section{EL DERECHO DE ACCESO A LA JUSTICIA DE LAS MUJERES INDÍGENAS EN EL ESTADO PLURINACIONAL BOLIVIANO}

\author{
Larissa C. de Sousa Ferro \\ Doutoranda em Ciências Sociais ELA/UnB \\ Universidade de Brasília \\ E-mail: larissa.csousaf@gmail.com \\ OrcidID: https://orcid.org/0000-0002-0767-3027
}

\begin{abstract}
Resumo: $\mathrm{O}$ artigo trata do acesso à justiça para as mulheres indígenas na Bolívia, com ênfase no período pós Constituição de 2009. A partir de uma perspectiva para além dos tribunais ordinários, o trabalho busca uma perspectiva que aborde as justiças indígenas e os processos sociais e políticos. Tratou-se de um apanhado histórico do contexto boliviano de luta dos povos indígenas e da participação das mulheres nessa luta. A pesquisa foi feita através da análise de documentos produzidos por órgãos internacionais e nacionais de/e ligados às organizações de mulheres indígenas, leis bolivianas sobre o assunto, além de entrevistas feitas durante os meus estudos de mestrado. A partir desse levantamento foi possível refletir sobre os avanços e desafios do acesso à justiça para essas mulheres, ao mesmo tempo em que também se buscou reforçar o papel dessas mulheres como detentoras de vozes e agencias no avanço à uma justiça intercultural de gênero.
\end{abstract}

Palavras-chave: Bolívia. mulheres indígenas. acesso à justiça. novo constitucionalismo.

Resumen: El artículo habla del acceso a la justicia de las mujeres indígenas en Bolivia, con énfasis en el período postconstitucional de 2009. Desde una perspectiva más allá de los tribunales ordinarios, el trabajo busca una perspectiva que aborde la justicia indígena y los procesos sociales y políticos. Fue un repaso histórico del contexto boliviano de la lucha de los pueblos indígenas y la participación de las mujeres en esa lucha. La investigación se realizó por medio del análisis de documentos producidos por organismos internacionales y nacionales de/y vinculados a organizaciones de mujeres indígenas, leyes bolivianas en la materia, además de entrevistas hechas durante mis estudios de maestría. A partir de esta encuesta, fue posible reflexionar acerca de los avanços y desafíos del acceso a la justicia por estas mujeres, al mismo tiempo que se buscó reforzar el rol de estas mujeres como portadoras de voces y agencias en el avance de la justicia de género e intercultural. 
Palabras clave: Bolivia. mujeres indígenas. acceso a la justicia. nuevo constitucionalismo.

Abstract: This article has the theme of access to justice for indigenous women in Bolivian territoty, with na emphasis on the post-Constitution period of 2009. Based on a view that goes beyond ordinary courts, the work seeks a perspective that adresses indigenous justice and social and political processes. It has a historical overview of the Bolivian contexto of the struggle of indigenous peoples and the participation of indigenous women in that struglle. The research was done through the analysis of documents produced by international and national bodias from/and linked to ingênuos women's organizations, the bolivian laws about the theme, in addition to interviews done during my master's studies. Based on this, it was possible to reflect on the advances and challenges of access to justice for these women, while also seeking to reinforce the role of these women as holders of voices and agencies in advancing intercultural gender justice.

Keywords: Bolivia. indigenous women. access to justice. new constitutionalism.

\section{Introdução}

As sociedades latino-americanas desde o início dos processos de redemocratização, pós-ditaduras dos anos 1980, passam por mudanças sociais e políticas nas quais se vislumbram as demandas pela elaboração de novas cartas constitucionais. Tais cartas vêm com o anseio da população por países mais democráticos e plurais, principalmente devido ao aumento da força dos movimentos sociais e da consolidação de temas como direitos humanos e meio ambiente no cenário internacional. $\mathrm{O}$ direito de acesso à justiça de forma igualitária e universal aparece neste novo cenário como um direito social fundamental e uma das premissas na busca de melhoria de vida das populações que foram secularmente marginalizadas, como as mulheres, as populações indígenas e negras. Os movimentos sociais e os próprios indivíduos perceberam essa esfera como grande oportunidade para a concretização de seus direitos que agora, em alguns casos, estão garantidos constitucionalmente, mas que na prática continuam a ser constantemente violados (FERRO, 2019).

No caso especifico das mulheres indígenas, o contexto se aponta ainda mais intricado por ser um grupo que lida no cotidiano com a intervenção de múltiplas exclusões, de gênero, de etnia e de classe. Dessa forma, o acesso à justiça para elas possuem empecilhos geográficos, econômicos, culturais e inclusive linguísticos quando se analisa o acesso à justiça estatal, e outros empecilhos, como os geracionais e de desigualdades de gênero quando analisamos o acesso às das justiças comunitárias indígenas, reconhecidas de maneira explícita constitucionalmente em alguns países, como no caso boliviano (CIDH, 2017). 
Na Bolívia, a nova Carta Constitucional possui reconhecimento internacional devido às suas inovações na busca de uma maior representatividade da plurinacionalidade do país. Uma dessas mais avançadas mudanças foi a decisão sobre os distintos processos de justiças indígenas como legítimos e soberanos, no mesmo grau hierárquico das demais decisões jurídicas. Ademais, diversos artigos sobre os direitos das mulheres se encontram presentes no texto como: a não discriminação, o direito da não violência (art.15), direitos sexuais e reprodutivos, equidade de gênero na participação política (art. 26) e o acesso à terra para as mulheres (art. 395 e 402) (BOLIVIA, 2009).

Há ainda um cuidado textual de ter sido produzido em uma linguagem inclusiva, não sexista, com a utilização de termos de ambos os sexos. Pequenos detalhes que demonstram, em certa medida, a atenção para as diferentes identidades e demandas de homens e mulheres, nesta caminhada da refundação estatal a partir de uma nação pluricultural, com respeito à diversidade. (AGREDA, 2012) Sendo assim o caso boliviano se tornou simbólico ao tratar de direitos indígenas na América Latina, em especial ao observarmos o direito a uma justiça intercultural e plurinacional. Dessa forma, o contexto boliviano se coloca como um relevante caso para se estudar a luta por direitos das mulheres indígenas e a busca pelo acesso à justiça.

A partir dessas primeiras ponderações, o presente artigo tem o intuito de compreender de que forma o acesso à justiça para as mulheres indígenas bolivianas tem ocorrido, focando principalmente no contexto do governo de Evo Morales (2006-2019) e a refundação estatal a partir do novo texto constitucional. Tal texto demonstrou avanços com a constitucionalização das justiças originárias indígenas e campesinas (JIOC), e as novas leis de combate às desigualdades de gênero (lei n. 348 e n. 243) dentro de um projeto que pretende descolonizar e despatriarcalizar suas estruturas de poder, dentre elas as estruturas do sistema jurídico boliviano. Exibiu também os desafios, ao buscar transpassar para a prática, seus princípios constitucionais e normativos, em especial aqui, sobre aqueles que inovam na busca de uma justiça intercultural e de gênero para as mulheres indígenas do país.

A análise realizada foi para além de um caráter descritivo e possuiu o intuito exploratório e reflexivo, uma vez que através da revisão bibliográfica densa do tema em questão procurou-se entender os motivos, desafios e dificuldades que permeiam o acesso à justiça para as mulheres indígenas bolivianas. Mesmo depois de uma refundação estatal, que, ao menos no texto constitucional e no discurso oficial, deveriam favorecer os povos tradicionais e seus direitos sociais, políticos e econômicos.

Para tanto, o artigo foi feito a partir dos resultados obtidos durante minha pesquisa de mestrado nos anos de 2017 a 2019. Essa pesquisa se fundamentou em reflexões a partir dos 
estudos subalternos latino-americanos para entender os conflitos entre a sociedade nacional e os povos indígenas desde o processo de colonização. Esses aportes ajudam a entender e desmitificar modelos que consideramos primordiais, como capitalismo, modernidade, e os próprios conceitos de Estado Nação e cidadão latino-americano (como homem branco, católico, proprietário e letrado) sendo essenciais para se entender a própria busca por consolidação dos direitos e acesso à justiça das minorias étnicas da região. Ademais, os estudos subalternos nos mostram a extrema importância de se olhar para os indivíduos não como objetos e sim como sujeitos capazes de agência e donos dos seus próprios destinos. Isso é essencial para a pesquisa em questão, uma vez que a busca por estudar os desafios de acesso à justiça para as mulheres indígenas não se pauta a partir de uma ideia de revitimizá-las e sim de apresentar seu potencial de agentes e produtoras de alternativas para os problemas criados a partir da colonização que elas e todos nós sofremos até os dias atuais.

A técnica de coleta de dados escolhida foi, sobretudo, a de análise de documentos e revisão bibliográfica. Os principais documentos analisados foram reportagens e entrevistas jornalísticas, dados e declarações de variados movimentos de mulheres indígenas e não indígenas bolivianas e intelectuais feministas indígenas acerca dos percalços do acesso à justiça no cenário boliviano e em geral na América Latina. Ademais a revisão bibliográfica de artigos acadêmicos, análises históricas e estudos etnográficos. A análise da última Constituição boliviana (2009) e das normativas que se seguiram que versão sobre direitos de mulheres e direitos indígenas foram feitas principalmente a partir da reflexão dos próprios textos normativos e alguns artigos acadêmicos que explicitam os silenciamentos de gênero em alguns momentos, principalmente nos que tratam do acesso à justiça. Os relatórios e diagnósticos feitos por ONGs internacionais como o Fundo de Desenvolvimento das Nações Unidas para a Mulher (UNIFEM - Países Andinos) junto com organizações nacionais e relatório da CIDH sobre as mulheres indígenas e seus direitos humanos nas Américas (2017), foram utilizados para compreender o problema em perspectiva macro de violações de direitos e as intersecções de desigualdades de classe, de raça e de gênero (FERRO, 2019).

Com a preocupação de buscar fontes que pudessem ir além do discurso oficial de Estado. Foram utilizadas fontes de ONGs nacionais, formadas por diversos setores da sociedade civil, dentre eles organizações de mulheres indígenas. A partir da Coordinadora de la Mujer ${ }^{l}$, foi possível ter acesso a documentos produzidos pelas organizações associadas, assim como às transcrições de encontros promovidos entre diferentes organizações de mulheres em La Paz,

\footnotetext{
${ }^{1}$ Rede que reúne 21 organizações não governamentais de mulheres indígenas e não indígenas na Bolívia. 
Cochabamba, Santa Cruz, Beni e outras cidades. A partir dos diagnósticos produzidos pela ONG Alianza Libres Sin Violencia foi possível acessar estudos em campo e entrevistas nos órgãos judiciais estatais. Tornando possível a análise a partir de uma visão não estatal dos serviços jurídicos pelo Estado boliviano e seus órgãos responsáveis pelos casos de violações de direitos das mulheres no país (FERRO, 2019).

Seguindo essa perspectiva não estatal, buscou-se a partir do coletivo de mulheres Aymaras denominadas Feministas Comunitárias Antipatriarcales, acessar informações sobre a realidade boliviana a partir do programa intitulado iDespatriarcalización ya! ${ }^{2}$, onde estão disponíveis diversas entrevistas com representantes de grupos de movimentos sociais de mulheres, mulheres representantes governamentais (ou ex representantes) e pensadoras feministas comunitárias que discutem os problemas das estruturas patriarcais, machistas e racistas no contexto boliviano e maneiras de superá-las. Ademais, acompanhou-se as plataformas digitais das organizações: a Casa de la Mujer, O Centro de Capacitación de la Mujer Campesina de Tarija (CCIMCAT), Agencia Plurinacional de Comunicación e Centro de Promocion de la Mujer Gregoria Apaza. Onde foi possível coletar considerável quantidade de informação sobre as organizações e também das estratégias de ações que estão sendo utilizadas por elas para superar as discriminações que vivem cotidianamente (FERRO, 2019).

Sendo assim, apesar de durante os estudos de mestrado não ter sido possível um eventual trabalho de campo em território boliviano, mostrou-se importante e enriquecedor o contato direto, por meios eletrônicos com organizações ligadas aos movimentos sociais formados majoritariamente por mulheres indígenas, ou que trabalham em consonância com elas, na luta diária contra as dificuldades de efetivação de seus direitos. Dessa forma, além das fontes citadas acima, o artigo também contou com reflexões a partir de entrevistas feitas com o grupo de mulheres Feministas Comunitárias Antipatriarcais de La Paz e com representantes do Centro de Capacitación e Investigación de la Mujer Campesina de Tarija (CCIMCAT), onde os nomes verdadeiros dos entrevistados foram mantidos, a pedido dos mesmos, com intuito de proliferar o conhecimento sobre suas organizações e trabalhos realizados.

\section{$2 \mathrm{O}$ acesso à justiça estatal boliviana}

\footnotetext{
${ }^{2}$ Disponíveis em : http://www.feminismocomunitario.com/despatriarcalizacion ${ }^{\circ} \mathrm{html}$
} 
A história da resistência indígena boliviana, assim como da maioria dos países na América Latina, vem desde os tempos da colonização, quando os povos originários passaram por grandes violações tanto físicas como epistêmicas. No caso boliviano, se mostra mais latente uma vez que quase $60 \%$ da população, ainda nos tempos atuais, é composta por povos indígenas que foram historicamente marginalizados dos direitos sociais e políticos (DOMINGUES, 2009).

Entretanto, é importante salientar que essa história não foi unicamente de perdas e violações, como o silenciamento da história oficial sobre essas populações tenta afirmar. As lutas e resistências ocorreram desde o início como marcado pelas figuras históricas de Tupac Katari e Bartolina Sisa ${ }^{3}$. Apesar da persistência do colonialismo interno no novo Estado nacional a resistência indígena à colonização e à marginalização dessas populações foram contínuas. Elas tiveram seu ápice nos anos 90 contra o governo neoliberal junto com os movimentos dos cocaleiros, cultivadores da folha de $\operatorname{coca}^{4}$, de onde surgiu o futuro presidente Evo Morales, e ganharam grande destaque durante as chamadas Guerra da Água (2000), protestos contra a privatização das empresas de distribuição de água, e do Gás (2002), levante popular contra a exportação do gás sem visar o abastecimento interno em primeiro plano. (FERRO, 2019).

Nesses processos, as mulheres indígenas foram sempre presentes, geralmente nos processos participativos internos de suas comunidades, mas também ultrapassando esses limites como o caso da líder Bartolina Sisa, citado anteriormente. Ademais, suas resistências cotidianas aos processos de colonização e colonialismo interno, mantendo tradições e rituais originários foram de extrema importância. Durante os protestos do ano 2000 e na ascensão de Evo Morales, as mulheres indígenas também se colocaram muitas vezes a frente dos movimentos, sendo um marco inclusive para o reconhecimento delas mesmas como grupos diferenciados.

O massacre do Gás, estar de frente do sistema de morte, frente às balas, por que havia militares disparando. Isso nos faz pensar o que é bom? Se o gringo não é bom, nós não somos bons para construir um mundo diferente, para viver com dignidade, o que é bom? Esse é um ponto em Bolívia que recobram a força dos povos indígenas. Não é que não existiam, que as mulheres indígenas não existiam antes disso. Mas que depois desse evento nos reconhecemos como aymaras, como quéchuas, publicamente (...) lá vimos que não somos iguais aos homens, não saíamos de casa, não estudávamos, não sabíamos do patriarcado nem do machismo não sabíamos o que significava isso. Mas vimos no massacre como nossos companheiros nos matavam. E como eles eram

\footnotetext{
3 O líder indígena e sua companheira orquestraram uma das maiores rebeliões na época da colônia, com especulação de participação de 40 mil homens e mulheres, durante uma resistência que durou 2 anos para ser sufocada em 1781 na região do Alto Peru, grande parte do atual território boliviano e sul do território peruano.

${ }^{4} \mathrm{O}$ cultivo e consumo da folha de coca pelas populações indígenas é uma cultura milenar e parte dos costumes andinos.
} 
irresponsáveis de ir em frente às balas. Foi nesse massacre, refletindo sobre o que vivemos nos definimos como feministas, por que aí nos demos conta de que nossos corpos não eram iguais aos dos homens. Porque mataram mais homens nesse massacre, os companheiros pensam que as balas não matam à eles, pensam que seus corpos são invencíveis. Nunca estão doentes, nunca tem medo. Nós sim tínhamos medos, por isso nos escondíamos das balas, mas também porque tínhamos que estar vivas para criar às nossas filhas, filhos, avós. Eles não porque não tinham responsabilidade de nada. Não tinham que voltar para casa para cuidar e limpar e nada. Então essas coisas nos fizeram refletir e pensar que eles tem uma vida diferente das nossas. Que nós gostávamos de estar na rua durante os protestos porque em casa tínhamos que limpar, cozinhar, toda uma vida, o que nos parecia normal, uma "vida de má sorte". Porque quando conversávamos na rua a uma se passava a mesma coisa, a outra também, a uma se batia, na outra também. Ai nos demos conta que acontecia com todas. (Entrevista de Adriana Gúzman in: FERRO, 2019).

A ascensão de Evo Morales ao poder nas eleições de 2006, como primeiro representante indígena do país, foi reflexo dessas constantes lutas e mobilizações dos povos indígenas, movimentos sociais de esquerda, e considerável apoio da classe média, contra os governos neoliberais e suas ações nos anos 90. Seu governo aparece como defensor das pautas formulada pelos movimentos sociais, na busca pela nacionalização de recursos naturais, contra o imperialismo colonial e patriarcal, e as realizações de reinvindicações históricas de movimentos indígenas, como de autodeterminação e autonomia além da promessa da formação de uma nova Assembleia Constituinte (STEFANONI, 2006).

A nova Constituição boliviana aparece concretizando esse movimento, já nos seus primeiros artigos, consolidando o projeto de Estado Plurinacional que aponta como parte essencial da nação boliviana as populações originárias indígenas e camponesas, mas não a partir de noções assimilacionistas como das normativas passadas e sim de maneira a respeitar sua autodeterminação e autonomia. Apontando ainda o objetivo da busca da descolonização de suas estruturas estatais, como a descentralização política através dos conceitos de plurinacionalidade e interculturalidade, já visíveis inclusive no próprio texto constitucional em se tratando da questão linguística, com a simplificação do texto e a incorporação de termos em Ayamara e Quéchua.

\footnotetext{
Artículo $2^{\circ}$

Dada la existencia precolonial de las naciones y pueblos indígena originario campesinos y su dominio ancestral sobre sus territorios, se garantiza su libre determinación en el marco de la unidad del Estado, que consiste en su derecho a la autonomía, al autogobierno, a su cultura, al reconocimiento de sus instituciones y a la consolidación de sus entidades territoriales, conforme a esta Constitución y la ley (BOLIVIA, 2009).
} 
Em se tratando de acesso à justiça, a carta inova principalmente ao reconhecer as justiças indígenas originárias campesinas (JIOCs) enquanto modos legítimos de resolução de conflitos, amparados em garantias constitucionais, com o peso simétrico diante de outras jurisdições ordinárias, podendo suas decisões serem revisadas apenas pelo Tribunal Constitucional Superior. A carta inaugurou um inovador pluralismo jurídico, ao mesmo tempo em que, o sistema judiciário estatal também se compromete a promover os valores da interculturalidade e igualdade de gênero nos art. 178 e 179 (BOLIVIA, 2009).

Outras normativas que vieram após a constituição, como a lei n 348 Ley Integral para Garantizar a las Mujeres una Vida Libre de Violencia (2013) e a lei n 243 Ley Contra el Acoso y Violencia Politica hacia las Mujeres (2012) apontam de maneira mais clara mecanismos de prevenção, disseminação de informação e punição de casos de violências contra as mulheres. Se atentando, inclusive, para as necessidades multiculturais das mulheres indígenas, enfatizando a necessidade de capacitação de mulheres urbanas e rurais (campesinas e indígenas) sobre o conhecimento de seus direitos e impulsionando a formação de promotoras comunitárias, demonstrando a importância da participação das mulheres dentro das comunidades rurais.

Entretanto ao olharmos para a efetivação desses mecanismos, diversos problemas nos saltam os olhos. A falta de informação é o primeiro desafio observado, uma vez que só é possível a busca por seus direitos a partir do momento de que se tem conhecimento deles. Outro percalço é a persistência da discriminação dessas mulheres em espaços públicos, devido à sua vestimenta, idioma e cor da pele. Os dados do Observatório de Gênero da Coordinadora de la Mujer mostram que entre as mulheres indígenas entrevistadas, 31,8\% (trinta e um vírgula oito por cento) relataram discriminação em espaços públicos por causa econômica e 27,2\% (vinte e sete vírgula dois por cento) por sua vestimenta, $26,8 \%$ (vinte e seis vírgula oito por cento) por sua condição de ser mulher e $21,1 \%$ (vinte e um vírgula um por cento) por seu idioma. Enquanto que para as mulheres não indígenas os números diminuem para 17,2\% (dezessete vírgula dois por cento) e $11,1 \%$ (onze vírgula um por cento), 13,5\% (treze vírgula cinco por cento) e 7,8\% (sete vírgula oito por cento) respectivamente (FERRO, 2019).

Essas discriminações recorrentes no cotidiano dessas mulheres se transformam em receios de serem ignoradas, maltratadas ou incompreendidas pelos oficiais de justiça. $\mathrm{O}$ despreparo dos policiais encarregados de recepcionar as denúncias de violência resulta na recusa daquelas enquadradas como violências psicológicas, uma vez que diversos funcionários não considerarem existirem elementos que provem a agressão. Esse cenário repercute em uma visão de pouca confiança no sistema de justiça estatal por essas mulheres. (FERRO, 2019). 
Ademais, há o obstáculo geográfico, uma vez que grande parte dessas mulheres se encontram em áreas rurais, longe dos grandes centros, onde ficam geralmente os locais de acesso à justiça. E mesmo quando conseguem chegar a esses locais, há o despreparo do pessoal em lidar com mulheres indígenas que muitas vezes não falam a língua espanhola. Por fim, ainda existe a ineficiência do próprio ordenamento jurídico estatal, onde por exemplo, segundo dados da Alianza Libres Sin Violencia, durante o primeiro ano da aplicação da lei n. 348 o Ministério Público teria recebido 11.000 denúncias, das quais apenas 30 tiveram sentença. Tais dados corroboram com a percepção comum de muitas mulheres que veem a justiça como ineficiente e dessa forma muitas vezes não chegam a buscar as autoridades ( $A L S V, 2017)$. Segundo dados da Coordinadora de la Mujer 64\% dos casos de violência contra a mulher estavam sem sentença, entre os anos de 2013 até 2016, e 60\% das mulheres indígenas dizem ter pouca confiança no sistema de justiça, fazendo com que na maioria dos casos de violações de direitos nem cheguem a procurar os órgãos estatais (COORDINADORA DE LA MUJER, 2019).

Esses dados do caso boliviano demonstrando os desafios enfrentados pelas mulheres indígenas no acesso às justiças estatais corroboram a problemática de maneira mais abrangente, em todo o continente. Esses obstáculos devem ser enfrentados a partir de pilares que apontem uma perspectiva multidisciplinar que requer prevenção, investigação, punição e reparação, a partir de uma visão intercultural e de gênero que leve em conta aspectos culturais, visão de mundo e diferentes concepções de justiça. A participação de maneira central da mulher indígena demandante do processo é um fator essencial para a ideia de reparação e justiça, auxiliando a vítima a reaver o sentido de controle da sua própria vida, assim como a identificação de desafios e prioridades (CIDH, 2017).

\section{$3 \mathrm{O}$ acesso às justiças originárias indígenas campesinas (JIOCs)}

As justiças indígenas originárias campesinas (JIOCS), como sistemas de resolução de conflitos existem durante séculos, desde antes mesmo do processo de colonização, e persistem até os dias atuais como forma de resolução de conflitos comunitário. Seja por estarem em lugares afastados dos grandes centros, onde o Estado não se faz tão presente, seja como forma de resistências anticoloniais de saberes jurídicos e culturais das próprias comunidades, mostrando melhor adequamento e legitimação para as populações a partir de seus diferentes valores culturais. Isso não quer dizer que são regidas por valores imutáveis, e assim como suas comunidades em si, também passaram, e ainda passam, por modificações significativas com o contato entre culturas, sendo ele forçado ou não, e advento dos meios de comunicação e difusão 
de informação. Entretanto, ainda mantêm estruturas singulares que às diferenciam do sistema de resolução de conflito ordinário (FERRO, 2019).

Com a nova Constituição o significado das JIOCs se expandiu para além da perspectiva culturalista ao constituir-se como resposta para limitações estruturais no acesso à justiça ordinária como a acessibilidade demarcada pelas distâncias geográfica e cultural, empecilhos linguísticos e custos econômicos. Constituídas de saberes, valores, práticas e procedimentos comunitários criam resoluções de conflitos prescindindo do marco positivo e fixo das normativas positivistas da justiça ordinária. A flexibilidade e dinamismo das JIOC possibilitam reformulações e mudanças a partir da reflexão comunitária e das particularidades dos casos em julgamento (DOS SANTOS, 2017).

[...] um fiscal que vem e dá uma sentença de algo que não conhece, não sabe como vivia a moça com o assassino, se ele sempre foi violento, se nunca contribuiu na comunidade, se não era respeitoso, não sabe nada. Então vem e diz que é inocente. Em contraposição, a justiça em comunidade serve porque não buscamos apenas o fato se não também se busca o caminho, a história da pessoa. Não buscam apenas ao moço, mas também a sua mãe, seu pai, seus próximos a comunidade, (Entrevista de Adriana Guzmán, in: FERRO, 2019).

Mesmo com essas características que as diferenciam das justiças ordinárias. As JIOC também são marcadas por casos de violências domésticas e abusos, situações em que as desigualdades de gênero e geracionais ainda reverberam. Quando se tem homens da comunidade ou familiares dos envolvidos como os responsáveis por realizar os julgamentos, o desafio é ainda maior. Ademais, persistem barreiras à representação política já que muitas vezes não se permite a participação feminina nas decisões comunitárias de forma igualitária. Nesse sentido, as mulheres indígenas vêm mediante arranjos coletivos, buscando questionar essas estruturas internas desiguais.

(...) a justiça comunitária (também pode ser) machista. Para outras coisas serve como: problemas de terras, de animais, os problemas da convivência comunitária, também há machismo aí, dão mais aos homens e coisas assim, mas se busca uma convivência. Mas não tão bem funciona para casos de violência contra a mulher, feminicidios, etc. Não é considerado um delito, uma falta, não querem falar. Nessas coisas não funcionam, em outras sim. Como na justiça ordinária há algumas coisas que funcionam, mas para as mulheres também segue sendo patriarcal (Entrevista com Adriana Gúzman in: FERRO, 2019).

A partir da pesquisa durante os estudos de mestrado, foi possível observar e sistematizar algumas das principais áreas sensíveis para as mulheres na busca de uma efetivação de seus direitos nas justiças originárias em contexto boliviano, sendo elas: as difamações (chismes), 
heranças de terras, participação nas decisões políticas das comunidades, brigas entre casais, adultério e violência intrafamiliar. Esses pontos não têm a pretensão de esgotar os casos em que podem ocorrer de violações de direitos das mulheres indígenas, mas sim mostrar de certa forma um panorama geral da situação (FERRO, 2019).

Dessa forma, é possível perceber que as questões relacionadas aos direitos das mulheres indígenas podem perpassar diversos conflitos tanto na justiça ordinária como nas justiças indígenas. As desigualdades de gênero existem nos dois sistemas, pois são frutos de um projeto colonial patriarcal que afetou tanto as sociedades nacionais como as sociedades indígenas, a partir do contato com o colonizador.

É importante ressaltar que a luta das mulheres indígenas pelo acesso à justiça, tanto nos âmbitos estatais quanto dentro das comunidades, não significa que elas são contra as justiças originárias, muito pelo contrário, os movimentos de mulheres indígenas estão constantemente reforçando os movimentos indígenas na busca pela consolidação de seus direitos coletivos de autonomia, inclusive de seus sistemas jurídicos. O que buscam é que esses direitos coletivos respeitem também seus direitos específicos, e inclusive que entendam os direitos das mulheres nas comunidades como um direito coletivo da comunidade para viver em harmonia e complementariedade, conceitos que suas culturas tanto prezam (FERRO, 2019).

Essa perspectiva visivelmente mais favorável das organizações de mulheres indígenas bolivianas pela resolução dentro das justiças comunitárias contrapõe com a lei $n^{\circ} 073$ de Deslinde jurisdiccional, onde, apesar de no texto constitucional está normatizado que as justiças originárias possuem mesmo grau de hierarquia que as demais justiças, nos casos mais graves de violação de direito das mulheres, como violência sexual e homicídio, devem ser levados diretamente aos organismos da justiça estatal e julgados por ela. Em seu artigo 10 são denominados os âmbitos que essas justiças não devem legislar, sendo eles:

(...) En materia penal, los delitos contra el Derecho Internacional, los delitos por crímenes de lesa humanidad, los delitos contra la seguridad interna y externa del Estado, los delitos de terrorismo, los delitos tributarios y aduaneros, los delitos de terrorismo, cualquier otro delito cuya víctima sea el Estado, trata y tráfico de personas, tráfico de armas y delitos de narcotráfico. Los delitos cometidos en contra de la integridad corporal de niños, ninãs y adolescentes, los delitos de violación, asesinato u homicidio (...) (BOLÍVIA, 2010, p.4, grifo nosso).

Entretanto, o que acontece muitas vezes é a desinformação das mulheres sobre essas normativas e, em diversos momentos, até as próprias autoridades originárias não sabem se devem ou não julgar os casos. E em casos que essas mulheres conhecem as normativas, ainda 
preferem não acessar a justiça ordinária por não acreditarem na sua efetividade de conduzir a uma sentença justa e intercultural ou até mesmo na efetividade de protegê-las, uma vez que esses órgãos ficam distantes das comunidades em que vivem (FERRO, 2019).

Ademais, existe a relação da mulher com a comunidade que não é considerada pela lei. Existem comunidades em que essas normativas não fazem sentido, seja por desconhecê-las, seja por não se sentirem seguras com a justiça estatal, ou por seus costumes não serem em resolver casos em outras instâncias. A comunidade não concordando com que se leve o caso para essas instâncias muitas vezes as mulheres decidem por respeitar a decisão comunitária prezando pela harmonia dentro da comunidade em que vivem (FERRO, 2019).

\section{Estratégias e articulações de ação dos movimentos de mulheres indígenas}

Durante a produção da pesquisa, no intuito de se observar articulações para além dos dados oficiais, foi possível constatar como as mulheres indígenas bolivianas têm buscado se organizar para alcançar um acesso à justiça de gênero e ao mesmo tempo intercultural, deixando o lugar de meramente vítimas de uma situação de supressão de direitos e se tornando agentes das próprias mudanças. Os seus incessantes trabalhos contam com o apoio de outras organizações de mulheres, ONGs e em certa medida também com organizações estatais e as próprias autoridades originárias homens dos movimentos indígenas. Um passo importante é a normatização de direitos que ainda não estão regulamentados, mas as realidades que elas vêm enfrentando, mostram que também é necessário ir além, para que ocorram mudanças estruturais nos seus cotidianos de exploração e discriminação.

Nessa perspectiva, a partir da pesquisa realizada foi possível rastrear as estratégias dessas organizações que tem sido principalmente investir em um trabalho de base com oficinas de capacitação, sensibilização e cura (sanación) (FERRO, 2019).

As oficinas de capacitação são aquelas voltadas para o aprendizado de direitos e normativas estatais que essas mulheres possuem como cidadãs bolivianas, além de buscar aprendizado em outros assuntos considerados primordiais pelas organizações de mulheres indígenas como a oficinas de artesanato e agroecologia, principais áreas profissionais dessas mulheres indígenas.

Já as oficinas de sensibilização são as oficinas feitas para/ ou em conjunto com homens indígenas das comunidades para sensibiliza-los sobre as desigualdades de gênero e questões de violência doméstica. A perspectiva de que violando os direitos das mulheres indígenas estão 
violando toda a comunidade como um todo é bastante usada por essas mulheres, na busca da compreensão dos direitos das mulheres em perspectiva comunitária.

Por fim, as oficinas de cura são espaços reservados para e entre as mulheres indígenas com intuito de dividir dores e casos de violação entre elas, criando uma rede de apoio feminino na comunidade, com a perspectiva de que coletivamente, é possível que elas possam se apoiar, se acreditar e por fim, se curar (sanar). (FERRO, 2019). É também a partir desses trabalhos de base que elas vêm construindo categorias e conceitos para compreender as diversas dimensões de violações de direitos que sofrem dentro e fora de suas comunidades a partir de uma perspectiva que leve em consideração seus valores e preceitos culturais. Como aponta Maria Eugênia Choque Quispe (in: MONTANO, 2016, p. 19):

La violencia es estructural, no solo está referida a la violencia física, psicológica, sexual, sino también las mujeres sufren una violencia espiritual, porque son violentados de manera integral. Violencia es también racismo, discriminación, marginación, patriarcalismo; la violencia pasa por todos esos escenarios. La mujer en estado de violencia se convierte en un objeto y todo el mundo te trata así; si vas a denunciar, pasas por todo el calvario para denunciar.

\section{Conclusão}

A análise feita nesse artigo encadeou diversas reflexões, não apenas sobre as questões iniciais e específicas colocadas do caso boliviano, como também indagações que foram levadas para a esfera latino-americana. A sintomática exclusão estrutural dos Estados Nacionais sobre populações indígenas e mulheres em um âmbito macro, mesmo depois das novas Constituições da região apontam os desafios que continuam latentes, mesmo depois da constitucionalização de novos direitos sociais, políticos e, aqui especificamente, jurídicos. Ademais, foi possível se atentar para a limitação do olhar inicial, predominado pela perspectiva institucional governamental, e buscar, mesmo que em perspectiva limitada, um olhar que se observa as relações extra estatais e solidariedade entre os diversos âmbitos da sociedade civil organizada.

Dessa forma, foi possível perceber que o histórico silenciamento histórico das mulheres indígenas como agentes políticos reais, não inviabiliza suas resistências milenares. Elas estiveram a frente dos movimentos questionadores ao colonialismo e ao neoliberalismo, estando juntas aos seus povos e na construção com os movimentos sociais do projeto de uma Bolívia Plurinacional. Estiveram na base do trabalho de criação e consolidação do próprio MAS e da eleição de Evo Morales, como o primeiro presidente indígena na Bolívia e adentraram esse governo ocupando papel de destaque na democratização dos meios de decisão e produção de 
normativas. Essas mudanças não se deram simplesmente de cima para baixo, como algo "dado" por um "governo bondoso", como aponta Adriana Gúzman (2019). Elas foram construídas a partir da luta milenar dos movimentos da sociedade civil e organizações sociais, inclusive de mulheres indígenas.

Conclui-se ainda, que já se mostra possível, e extremamente necessário, que sejam feitas leituras e estudos mais críticos e realistas a respeito do que se convencionou chamar Novo Constitucionalismo Latino-Americano. Essa conclusão não busca, em nenhum dos seus aspectos, deslegitimar os avanços louváveis feitos principalmente em relação aos direitos sociais, coletivos e de mulheres. Mas sim provocar reflexões sobre tais ordenamentos jurídicos que declaram explicitamente a multiculturalidade e plurinacionalidade das sociedades nacionais, e a intenção de projetos de despatriarcalização e das estruturas de poder, incluindo do próprio aparato jurídico ordinário. Ademais, é preciso olhar para as problemáticas reais que conceitos essencialistas podem gerar na criação ou consolidação de outras estruturas de desigualdades.

A sistematização de normativas, leis e políticas de governo inovadoras demostram grandes avanços adquiridos durante o governo indígena-popular, em especial com a aprovação da Carta Constitucional. Todos esses aparatos jurídicos dão prerrogativa para que as lutas continuem acontecendo. $\mathrm{O}$ direito se mostra como campo de disputa discursiva, de legitimação de narrativas, uma luta constante pela nomeação e a consagração jurídica das narrativas sobre injustiça, espolio e sofrimentos. "Por dar poder juridicamente aos nomes que já se encontram em uso e por publicitar e colocar em uso, na boca das pessoas as palavras da lei”. Para que as palavras da lei passem a valer para além dos tribunais, mas também nas relações do cotidiano, e que os Estados reconheçam e garantam a existência de populações historicamente ignoradas e sobrepujadas (SEGATO, 2016, p. 129, tradução nossa).

Entretanto, a partir das reflexões feitas nesse artigo é possível afirmar que essas mudanças normativas, apesar de extremamente louváveis, não foram satisfatórias para a consolidação de mudanças estruturais de descolonização e de despatriarcalização. Até mesmo, no caso o boliviano que é apresentado muitas vezes como avançado em relação aos direitos coletivos interculturais, os percalços ao tratar de garantir que os direitos das mulheres indígenas sejam efetivados ainda estão presentes. A luta para que seja respeitada uma vida sem violência e com dignidade, a partir de uma perspectiva intercultural como das mulheres indígenas ainda persiste nos dias de hoje. 


\section{Referencias}

AGREDA, Evelyn. R. 2012. Del proceso constituyente al vivir bien desde la mirada de las mujeres. In: Mujeres en diálogo: Avanzando hacia la despatriarcalización en Bolivia. Coordinadora de la Mujer, La Paz, Octubre de 2012.

ALIANZA LIBRES SIN VIOLENCIA (ALSV) 2017. Calidad y Efectividad de los servicios de las instituciones públicas responsables de la atención, persecución y sanción de la violencia contra las mujeres en Bolivia. La Paz, 2017.

BOLIVIA Constituição (2009). Constituição do Estado Plurinacional da Bolívia. Sucre, Chuquisaca. 7 de fev. 2009, 107 p.

\begin{tabular}{ccc}
\multicolumn{2}{c}{ Lei no. 243 de 28 de mai. de 2012. Ley contra el acoso y violencia política hacia } \\
las & mujeres. & Disponível
\end{tabular} https:/www.ilo.org/dyn/natlex/docs/ELECTRONIC/90299/104007/F226460565/BOL90299. pdf>. Acesso em: 22 out. 2020.

. Lei no. 348 de 9 de mar. de 2013. Ley integral para garantizar a las mujeres una vida libre de violencia. Disponível em: $<$ https://www.migracion ${ }^{\circ}$ gob.bo/upload/1348.pdf $>$. Acesso em: 22 out. 2020.

. Lei no. 073 de 29 de dez. de 2010. Ley de Deslinde Jurrisdiccional. Disponível $\overline{\mathrm{em}}:<\mathrm{https}: / /$ bolivia.infoleyes.com/norma/2769/ley-de-deslinde-jurisdiccional-073>. Acesso em: 22 out. 2020.

$\mathrm{CIDH}$, Corte Interamericana de Direitos Humanos. Relatório mulheres indígenas e seus direitos humanos nas Américas. OAS Official records, 2017. Disponível em: https://www.oas.org/en/iachr/reports/pdfs/IndigenousWomen.pdf. Acesso em: 22 out. 2020.

DOMINGUES, José Maurício. A Bolívia às vésperas do futuro In: A Bolívia no espelho do futuro. DOMINGUES, José Maurício et. al. (Org.). Belo Horizonte: Editora UFMG, 2009.

FERRO, Larissa Cristina de Sousa. O Acesso à justiça para as mulheres indígenas no Estado Plurinacional Boliviano. (Dissertação de Mestrado, Universidade de Brasília), Brasília, 2019.

GUZMAN, Adriana Arroyo. Entrevista concedida em 26/04/2018 por meios eletrônicos, Brasília, 2018.

MONTANO, Sonia. Violencia contra la mujer em Bolivia: leyes que no se cumplen ${ }^{\circ}$ Diálogo Académico e Investigaciones. Revista T’inkazos, n`39, 2016, pp.9-26.

SEGATO, Rita Laura. La guerra contra las mujeres. Editora Traficantes de Sueños, Madri, Espanha, 2016.

STEFANONI, Pablo. El nacionalismo indígena en el poder. In: OSAL-Revista Observatorio Social de América Latina, Año VII, no 19, enero-abril, 2006. 
Data de recebimento: 11.022.2021

Data de aprovação: 19.03.2021 